\title{
Constructing A Scale For The Achievement Motivation In Learning Science At The Primary Stage Based On Atkinson Theory
}

\author{
Manal Mohammed Khaleel Abu-Za'rour \\ Monim Abdulkareem Al-Sa'aideh \\ Faculty of Educational Sciences, University of Jordan, Jordan
}

doi: 10.19044/esj.2016.v12n14p329 URL:http://dx.doi.org/10.19044/esj.2016.v12n14p329

\begin{abstract}
The aim of this study is to construct a scale to measure the achievement motivation in learning science at the primary stage. The study population consists of the students of the third primary class. The study subjects were 193 students. The scale validity was confirmed through four methods: arbitrators' validity, content validity, factor validity, and the correlation validity of the scale items with the total degree and domain degree. The scale reliability was ensured through two methods: test-retest and the internal consistency. Results showed acceptable significant validity and reliability of the scale. The coefficient values of the item saturation with their domains (factor validity) were 0.347-0.802. Co-efficient co-relations of items with the total degree were 0.332-0.550. Also, the correlations of items with their domains were 0.438-0.694. As for the scale reliability, the internal consistency value (Cronbach's Alpha) was 0.703 and 0.802 by using the stability coefficient.
\end{abstract}

Keywords: Scale construction, measures of achievement motivation, internal consistency

\section{Introduction}

Individuals' motivation influences their behavior. Motivation makes them behave in a certain way. Sometimes, individuals behave in certain situations as result of unconscious motives that they might not be aware of. However, it is necessary to realize the motivations which influence the individual's behavior in a certain situation in order to understand their behavior in that situation (Abu-Reyash et al., 2006).

Motivation constitutes a meeting place for those working in the field of Psychology since it is the source of human energy. Also, it serves as the basis of forming individuals' habits, values, interests, and practices. It also 
has a major role to play in the modification of their behavior and in guiding them towards achieving the desired aims (Abu-Jadou, 2012).

Petri \& Govern (2004) argued that motivation works on mobilizing the individual's behavior and it guides them to satisfy a certain need or to achieve a certain aim. It is considered as a form of urgent excitations that create a kind of activity and efficiency. Rao (2003, p.8) defined it as "an effective power or interest (learned or innate) that works inside the individual to force them or convince them or inspire them to work in order to fulfill their basic needs or to achieve some of their specific purposes.”

Rao (2003) indicates that motivations originate because of the need that internally stimulates the individual's activity. Also, it guides it towards the aim that leads to the satisfaction of the needs. Biological needs produce biological motivations, such as hunger and thirst, and are connected with the survival of the organism. Psychological needs, on the other hand, produce social and psychological motivations such as fear, anxiety, and achievement. However, incentives are influenced by praise, estimation, and reward. Social needs are connected with the social and cultural environment and the psychological structure of the individual.

Touk, Qatami \& Adas (2003, p.269) define motivation in its general meaning as "an internal state that stimulates individuals' behavior and works on the persistence of such behavior through guiding it towards achieving a certain aim.”

Motivation in the educational process is considered as one of the most important factors. Its weakness stops learning from taking place. Therefore, developing motivation is considered as an aim in itself in addition to its being a means (Al-Otoum, 2008). As for being an aim, motivation serves as the most important purposes of teaching. Teachers usually seek to stimulate students' motivation before beginning teaching subjects. As for being a means, motivation is a means to achieve the educational targets as well as being an important factor that helps in achieving knowledge, understanding, and in acquiring skills (Abu-Allam, 2010).

Highly-motivated students gain highly effective achievement, while low-motivated students may raise riots at the class. Living organisms get their activity increased once their motivation increases. Therefore, such behaviors persist until their motivation has been satisfied. If the individual gets tired while seeking to satisfy their motivation, they may have to rest for a while and then carry on their activities. If they encounter any difficulties that prevent them from satisfying their motivations, they would change their behavior to adapt with the new situation that prevents them from satisfying their motivation (Woolflok, 2001).

Motivation helps us in explaining the individual differences among students in school achievement. This is especially when such differences are 
referred to factors other than intelligence or aptitude to study. Most of the time, we find that our students have low abilities, but are distinguished with high school achievement. On the other hand, other students are highly intelligent, but have low school achievement. This means that our expectations of achievement vary positively or negatively from what is actually taking place. High or low achievement motivation is responsible for that. Students whose achievement is lower than expected of them are usually not motivated to achieve at certain degree. However, this achievement is usually at a level that is appropriate for their aptitude. On the other hand, students whose achievement is higher than what is expected of them, make great effort in studying because of the high achievement motivation. Therefore, there is a strong relationship between achievement motivation and performance (Abu-Allam, 2010; Al-Mubasher, 2009; Kriebaum \& Spinath, 2016).

Motivation of achievement is considered as a distinctive case of general motivation. This motivation expresses a desire that aims to perform an action well and in a way that leads to its success. It is characterized with ambition, independence, and the enjoyment of competitive situations. Thus, this is in addition to preferring performing tasks with intermediate levels of risks to performing tasks with little or high risk (Qudah \& Tartouri, 2006; Qatami \& Adas, 2006).

The way of satisfying the need to accomplish is specified by individuals' interests. The need to achieve in the physical domain takes the form of the desire to achieve sporting success. Also, the need to achieve in the mental domain takes the form of mental excellence. Therefore, the domains of life through which one may satisfy this need are many (Al-Jalali, 2011). Achievement motivation leads the individual to work hard and to do their best in seeking something. Through this way, a student works hard to achieve the main aim or purpose they seek. Thus, they are given great care and attention. This motivation is different from one student to another and from one nation to another. It is also influenced by many factors that vary in their effect on human beings (Nasralla, 2004; Kriegbaum \& Spinath, 2016).

Achievement motivation is considered as one of the important factors for school success in all educational stages. It is considered to be very important during the first years of study since it guides learners' behavior towards achieving acceptance in the situations that require academic excellence. As a result of this, motivation becomes a strong and domineering factor in the academic life of the learner since teachers' acceptance of learners depends on their maintenance of this high level of achievement (AlJalali, 2011; Decaro, DEcaro \& Rittle Johnson, 2015).

Psychological theories which are concerned with explaining motivation are numerous. Thus, some of these theories are presented below: 
Behavioral Approach is based on interpreting human behavior through the concepts of stimulus, response, reward, and punishment. It argues that external environment controls the individual response, and that the internal interactions are not of interest. Therefore, stimuli control behavior (Woolflok, 2001). This approach attributes motivation to external effects which activates individuals' behavior. If this is linked with a pleasant experience, the possibility of repeating and learning would increase. Also, if it is linked with a harmful experience, the possibility of repeating it falters and might fade away. Therefore, man, in the frame of this theory, is motivated to obtain the reinforcement and to avoid the punishment (Al-Ziq, 2006).

Social learning stems from the supposition that man is a social creature living within groups that influence him. On the other hand, these groups are also influenced by him. Man observes the behaviors of others and he imitates them. The measures of reinforcement or punishment have a major role to play in the possibility of learning or in not learning such behaviors. When the behavior pattern is reinforced, individuals attempt to imitate it in order to get the reinforcement. If the pattern is punished, the individual attempts to avoid it. Thus, lots of human motivations are acquired through the process of observation and imitation according to the outcomes of the behavior of others (Zghoul, 2012).

The cognitive approach argues that individuals do not automatically act in response to external or internal stimuli. Instead, their reaction is based on the results of the cognitive processes they are involved with. Hence, this is based on these stimuli. This approach emphasizes that man is a rational being who has a well that enables him to act the way he considers appropriate. Furthermore, there are some factors such as intention, expectation, and justification which influence his behavior. Thus, it emphasizes the internal resources, interests, and plans which individuals seek to satisfy through their behavior (Zghoul \& Hindawi, 2010).

Atkinson's theory is one of the cognitive theories that addressed achievement motivation. However, Atkinson defines achievement motivation as a motive that moves and guides the individual to achieve success in the activities that represent a standard of excellence or the activities that include clear standards of success and failure such as cognitive or social activities (Qatami, 2005, 183).

Opinions about the source of achievement motivation are multiple. Murray considers it as a personal attribute among individuals. Thus, this attribute is fixed. All individuals have a collection of physiological and psychological needs that they try to satisfy. Other researchers believe that achievement motivation is influenced by social education practices. They also opine that the family has a great role to play in developing achievement 
motivation among its members. Achievement motivation varies among individuals according to the encouragement, support, and competitive opportunities that are offered to them (Zghoul, 2012). It has been emphasized that mothers of the children whose achievement motivation was high were keen on providing them with independence at home. On the other hand, mothers of the children whose achievement motivation was low did not encourage their children to become independent. As a result of being influenced by the practices of social education, there is a clear difference between individuals of the same society and of different cultures. Thus, this differences stems from the different patterns practiced through social education, which differs from one class to another. In general, classes and cultures which encourage independence produce individuals with high achievement motivation (Qatami \& Adas, 2002). A third party of researchers argues that achievement motivation depends on the nature of expectations connected with the success or failure experience which is formed based on previous experience (Zghoul \& Hindawi, 2010; Decaro, DEcaro \& Rittle Johnson, 2015).

McCelland states that achievement motivation is connected with the activities performed by man. However, these activities vary from one individual to another depending on the Locus of Control. Individuals with high achievement motivation enjoy an internal locus of control (internal reinforcement). Thus, this means that they have self-control, affinity towards the task, and perseverance in order to achieve the task without caring about the external reinforcement given to them. In this respect, family education plays a vital role in raising this motivation. Individuals, who are raised on self-control with an inclination towards completion and excellence, almost have an internal inclination towards achievement as a result of the achievement motivation itself which is not a result of reinforcement (Zghoul, 2012).

Atkinson is not much different from McCelland. Nevertheless, he added another aspect to achievement motivation which is the individual's need to avoid failure. Atkinson put forward his theory in the frame of expectation- value inclination. He shed light on the factors that define achievement based on risk. He stated that risk, in any action, can be defined by factors that are concerned with the individual qualities and other factors that are related to the characteristics of the work or task that is to be achieved. Thus, these factors are as follows:

\section{Characteristics that are related to Individual Qualities}

Atkinson believes that there are two types of individuals who react differently in the area of inclination towards achievement. These two types come as a result of interaction between the level of the need to be achieved 
and the level of anxiety or the fear of failure. Psychologists who examined achievement motivation focus on these two parallel types. The first type individuals (those controlled by achievement motivation) have a higher degree of the need to achieve than the fear of failure. Therefore, they have a strong motivation to succeed and a low motivation to avoid failure. It is expected that they show achievement guided towards activities because their anxiety of failure is so limited. On the other hand, the individuals of the second type (those controlled by failure avoidance motivation) have a high degree of fear of failure compared with the need to achieve. As a result, they have a low motivation to succeed and a high motivation to avoid failure. In this way, it is expected that they do not have an achieved activity or they might have it but with a limited degree. They lack the need to achieve as the fear of failure dominates their actions.

\section{The Task Characteristics}

Atkinson argues that there are two factors that work differently. The first factor is the possibility of success which indicates the perceived difficulty of the task and which is considered as one of the risk limitations. The second factor is the stimulus to succeed in achieving the task since the performance of any task is influenced by the motivation to succeed in this task. Therefore, this refers to the person's internal interest to do the task.

Atkinson addressed the motive to succeed in a certain task in the light of its relation to the difficulty of the task. He supposed that if the task difficulty increases, the motive to succeed also increases. Since such actions are accompanied with a high motive, the individual considers it to be important in achieving the task successfully. In the case of the task being easy, it will be accompanied by a low motive since satisfaction becomes low upon achieving it.

In the light of what has been previously mentioned, the relationship between the factors that determine achievement motivation- whether they are concerned with the inclination to achieve success or the inclination to avoid failure - are as follows:

1. Inclination to Achieve Success: This indicates the onset motivation of the achievement situation. It is determined through three factors, namely: the motivation to succeed, the possibility of success, and the value of the success motive in performing a certain task. Highly motivated individuals feel proud due to their achievement because they derive joy in achieving success.

2. Inclination to Avoid Failure: This negatively influences entering into the achievement situations. It is determined by three factors, namely: the motive to avoid failure, the possibility or expectation of failure, and the value of the failure motive. 
The motive to succeed and the motive to avoid failure are two variables that are derived from the personality characteristics. Some individuals have a high inclination to achieve success, while others have an increasing inclination to avoid failure (Khalifah, 2000). However, the individual's motivation and the effort made to achieve success depend on the range of the need persistence. If their need towards achievement is more than their need to avoid failure, their motivation towards achievement will be stronger. On the other hand, if their need to avoid failure is stronger than their need to succeed, their level of motivation will be weak (Zghoul, 2012).

Achievement motivation takes the form of a desire to achieve an unattainable thing, to overcome barriers, to seek success, and to achieve a desirable conclusion. Individuals with high achievement motivation are characterized in making serious efforts to approach a high degree of success. This is in addition to being more organized, realistic, co-operative, and customs-abiding than individuals with low achievement motivation (Obeidi, 2009).

In light of what has been previously mentioned, achievement motivation can be defined as 'The individual's desire to excel in life according to their own interests and to do their best to challenge hardships.' Its strength (strong or weak) and its direction (embarking on or reluctance) towards performing the task with the area of interest is limited according to the interaction between the individual's attributes and the task attributes. If the individual's desire in achieving success in a certain task exceeds his/her desire to avoid failure, if the possibility of succeeding in performing it increases, and the value of success motive also increases, it leads to an increase of its strength and has a positive inclination towards achievement. If the individual's desire to avoid failure in a certain task exceeds his/her desire to achieve success, if the possibility of achieving it is low, and the value of the success motive is also low, it weakens and it negatively inclines towards the reluctance of achieving the task in order to avoid failure.

There are variant effects of success and failure on the individual's behavior. If their achievement motivation exceeds their motivation of fear from failure, their desire to perform a certain task is reinforced. This occurs especially if they are exposed to a moderate quantity of failure. Since they are determined in achieving, they try to make an attempt once again. Success, which is easily achieved, reduces the motivations of individuals who have an inclination towards achievement motivation. In addition to that, the effects become opposite among learners motivated by fear of failure. This occurs since failure frustrates them, while success encourages them (Abdul-Hadi, 2004; Gwo-Jen • Chun-Ming • Nian-Shing, 2013).

Consequently, there are differences between highly motivated individuals and low motivated individuals. Highly motivated individuals 
prefer selecting moderately-difficult tasks with some challenge. However, they refrain from selecting very easy tasks, because such tasks lack challenge. In addition, they also refrain from selecting highly-difficult tasks because of the high possibility of failure. Highly motivated individuals are characterized by their desire to get a feedback about their performance. Therefore, they prefer tasks that grant rewards on an individual basis and they do not enjoy tasks whereby rewards are granted equally to all individuals (Alawneh, 2004).

The concept of learned helplessness represents the extreme aspect of the failure motive. It indicates the individual's perception that whatever he does, he would inevitably fail. This perception leads to helplessness or motivational defect (which is related to a decrease in the willful responses rates of the individual); cognitive helplessness or defect (which is related to learning difficulty because the individual's future responses do not lead to some results); and emotional helplessness or defect (which is related to the sad feelings of an individual experiences, in addition to losing interest in the life activities and in others) (Abu-Jado, 2012; Magnano, Craparo \& Paolillo, 2016).

Although there are two main motives behind the achievement motivation which are the "the need to achieve" and the "fear from failure", we still have an unanswered question. This question is: "What leads people to seek success or to avoid failure?”

The different meaning given by individuals to the output of their actions may create emotional and behavioral reactions towards these outputs. The meanings of these outputs resulting from motivations should also be taken into consideration. People possess different beliefs about the personal attributes that are being evaluated in the achievement situations. Some of them believe that the performance tasks measures their basic intelligence, while others consider that such tasks provide them with an indicator about their present level of the skill that can be acquired. These beliefs are not a kind of attribution that people make after success or failure in performing some tasks. However, they are beliefs about the nature of that ability and how the future tasks are reflected on that ability (Sansone, 2000).

It is necessary for teacher to identify learners who are motivated by the need to achieve and those who are motivated by the need to avoid failure. Students who have a high motivation for achievement are inclined to respond more than others to the tasks which require challenge, to the new and extraordinary problems and to repeat their trials after failure. Students who are concerned with avoiding failure are inclined to respond to less difficult tasks and to constant reinforcement of success, to the small steps in learning and in avoiding and openly declaring their mistakes (Abdul-Hadi, 2004; Forgeard \& Seligman, 2012). 
Individuals who have a high achievement motivation work more seriously than others and achieve more success in their life and in various life situations. When comparing these individuals with those of the same level of mental ability, but with a low achievement motivation, the first group was found to record marks in the speed test of achieving the arithmetic and verbal tasks. It also plays the role of problem solving and in obtaining admission into a better school and having a better university results. However, they also make remarkable progress in the society. High achievers are realistic in ceasing opportunity unlike low achievers who are usually satisfied with simple reality. These achievers, however have an ambition that is far greater than their ability to achieve (Santrrock, 2003; Froman, 2010; Giorgi \& Majer, 2009).

Learning science in the primary stage encourages students to ask questions that help them understand and explain the natural phenomena around them. It also provides them with the basic knowledge that enables them to effectively make contributions in their societies. It also helps them acquire ideas, concepts, and generalizations which helps them in understanding and explaining the facts and their life applications. It also prepares them to think scientifically and to acquire a part of the general culture that allows them to identify the most important scientific achievements and discoveries. Thus, this helps them to gain positive skills and attitudes, actively participate, and live in the $21^{\text {st }}$ century (The Ministry of Education, 2013). In order to achieve these aims, teachers should develop the achievement motivation to learn science among their students. Qudah \& Tartouri (2006) suggest that this can be achieved through the following strategies:

1. Use of Feedback: Providing students with feedback on the reasons for their success or failure increases the achievement prospects among them. When a student finds it difficult to perform a certain task, the teacher must make use of the student's successful past achievement. This helps to build the confidence of the student and make him have the feeling that he has the ability to learn the new task. When the student gets involved in the work, the teacher must encourage him by using the appropriate statements.

2. Enabling Students to Set their Own Aims: Here, teachers encourages students to set their own learning aims, to use their own language, and to discuss these aims with them. Through this way, students' achievement motivation increases.

3. Stimulate Students' Need for Achievement: The need to achieve is available among all students but at varying degrees. This level may not be high enough to enable students to make the proper effort to succeed. Therefore, teachers must pay attention to these students especially if they show lack of interest in performing the tasks assigned to them. Thus, when 
teachers assign relatively simple tasks to these students, their achievement motivation will be stimulated. Also, their desire in making their efforts to succeed will be increased since success reinforces their self-confidence and forces them to make more efforts.

Studies that addressed constructing or developing achievement motivation scale are various. For example, Sumita Rao (2012) conducted a study with the aim of constructing a scale for achievement motivation. However, this primarily consisted of 115 items and was piloted on 300 male and female students. To confirm the scale validity, face validity was confirmed by showing it to three arbitrators. In the light of their comments, 90 items were selected and the remaining items were discarded. The discriminatory validity was calculated to determine the scale ability and to discriminate between highly motivated students and low-motivated ones. Items that do not have a high ability of discrimination between students according to the achievement motivation (high, low) were omitted. In this way, the final form of the scale consisted of 80 items. Deo Mohan scale was used to confirm the concurrent validity. The coefficient correlation between the two scales was 0.53 . To ensure the scale reliability, retest method was used and the reliability coefficient was 0.83 . Thus, these values were considered appropriate for the study purposes.

A study was conducted by Al-Mubasher (2009) with the aim of investigating the effect of mixed learning on the achievement of the $10^{\text {th }}$ grade students in the subject of "Islamic Education" and the achievement motivation among them. The achievement motivation scale prepared by Awad (2004) was modified to suit the Kuwaiti environment. The scale, in its primary form, consisted of 42 items distributed on three domains: Perseverance, ambition, and aim. The scale was shown to a group of arbitrators. In the light of their opinions, the wording of some items was modified and other items were omitted. Hence, the scale consisted of 33 items. The internal consistency of the scale domains was produced by using Cronbach's Alpha. The value was 0.83 - 0.89. The values were considered appropriate for the purpose of the study.

Al-Muhsen (2006) conducted a study which aimed at detecting the perceived self- competence and its relation to achievement motivation and compatibility among the students of the Faculty of Education at Yarmuk University. A scale to measure achievement motivation was developed which utilizes a number of relevant studies. The scale consisted of 20 items which were answered by using a five-point Likert scale. Validity significance of the scale was found by using logical validity. To calculate the reliability of the scale, retest method was used. Pearson co-efficient between the two applications was 0.89 , which is a value that is considered appropriate for the purpose of the study. 
Sabri (2005) investigated the efficiency of an educational program in teaching optimism and developing the knowledge and achievement motivation among the $6^{\text {th }}$ grade students in the schools of north and south Amman that are affiliate to UNRWA in Jordan. Sabri modified the scale prepared by Hermans. This scale was translated by Mousa Farouq (1987) into Arabic. In addition, he also calculated the criterion validity through linking its performance with achievement. Validity was 0.76 . The scale in its Arabic form consisted of 28 items. Each item was an incomplete sentence followed by five phrases (a, b, c, d, and e) or four phrases (a, b, c, d) which could be used to complete the incomplete sentence. The five-point scale was applied on 19 items, while the four-point scale was applied on the remaining 9 items. Arbitrators agreed that all scale items are appropriate. As for the language wording, some modifications were suggested for some items. However, they criticized the scaling of response. Therefore, a fifth distractor was added to the items of four-point scales. Using the factor analysis, the items received a saturation percentage of 0.28 or more. For construct validity, the researcher calculated the correlation coefficient of the items with the total degree of the scale. The values ranged between 0.25 and 0.65 . The test-retest reliability method was used. Therefore, the correlation coefficient between the first application and the second application was 0.88 . Reliability was also calculated by using Cronbach's Alpha on the data of the scale pre- application. The reliability coefficient was 0.82 . Therefore, both values were considered appropriate.

Ziad (2004) conducted a study to investigate the relationship between achievement motivation and classroom environment among the $12^{\text {th }}$ grade students. Also, the researcher developed Attiyyah scale (2002) and showed the scale in its Egyptian form which consists of 15 items to a group of arbitrators at Nasserite to explore their opinions regarding the number of the scale items. Modifications were made in the light of their suggestions. The scale in its Egyptian form was applied on a sample of 60 male and female students. Data was collected and analyzed and the correlation of the item with the total degree was calculated for each domain. This was done so as to omit the items which correlation coefficient is less than 0.30 , and to modify the items that received the highest comments from the committee members. The best ten items for each domain were selected. In carrying out some modifications on the scale structure, the scale reliability was calculated in its new form by using test-retest method on a sample of 30 male and female students with an interval of two weeks. Pearson correlation coefficient was calculated between the two applications and was $0.76-0.82$. The reliability of the total degree was 0.85 . The coefficient of the minor domains consistency was calculated using Cronbach's Alpha and was 0.71- 0.83.The scale reliability was 0.86 . 
These studies were beneficiary in specifying the items and procedures. This study is similar to previous studies regarding the procedures followed to ensure validity and reliability. However, it is different in that it is, as far as the researchers know, the only study that aimed to construct a scale to measure the achievement motivation for the lower primary stage. In addition, it is based on a specific theory in the interpretation of achievement motivation, particularly in learning science.

\section{The Study Problem}

Studying the achievement motivation among students is very important since the amount of the effort made by students to achieve excellence and success depends on their achievement motivation. Students with high achievement motivation make great effort to achieve excellence, while students with low achievement motivation do not make such effort because the need for achievement is not persistent with them. Therefore, teachers should identify the students of high achievement motivation and those of low achievement motivation. This makes it necessary to provide a scale that enables science teachers to determine the individuals of each category. Therefore, the idea of this study came out with building a scale to measure achievement motivation in science.

\section{The Study Questions}

1. What is the significance of the validity of the achievement motivation scale that is expressed by the significance of face validity, content validity, factor validity, and validity of the item correlation with the total score of the scale and the domains they are included in?

2. What is the significance of the reliability of the achievement motivation scale expressed by Cronbach's Alpha method and Pearson correlation coefficient?

\section{The Study Importance}

The importance of this study stems from the construction of an objective instrument to measure achievement motivation according to Atkinson's theory of motivation. As far as the researchers know, this is the only study that adopted this theory to construct a scale of achievement motivation. Its importance lies in providing an instrument that has acceptable validity and reliability significance. It also aims at providing the instrument for those working in the educational field to enable them to measure achievement motivation. Another importance lies in the importance of the subject itself since achievement motivation is considered as the basis to achieve excellence in all walks of life, particularly academic excellence. 


\section{Study Sample}

The study sample consisted of 193 males and females of the $3^{\text {rd }}$ grade students at the schools of the Islamic Educational College/Al-Rasheed Suburb affiliate to The Directorate of Education, Al-Jami'ah District at Amman, the Capital. The sample was collected from six sections for the scholastic year (2015-2016).

\section{Study Instrument}

The following steps were done in order to construct the scale:

1. Literature review of some studies that developed scales for motivation such as the study of Tuan, Chin \& Shieh (2005) and Waugh (2002).

2. Adopting Atkinson theory of achievement motivation and formulating the scale items in its light. The scale primary form consisted of 22 items distributed on three domains that are considered as the basic factors that constitutes achievement motivation.

- The items of the first domain (motive to achieve success) address the need to achieve opposite to the fear from failure. This is through formulating items that reveal the range of the need to achieve persistence among students. Thus, this was obtained through revealing whether their need to succeed was stronger. As a result, they embark on the different situations, or their need to avoid failure is stronger. Also, they refrain from the situation. For the second domain (Success probability) which points out the perceived difficulty of the task, items were formulated in a way that reveals the range of students' expectation that they can succeed in various situations.

- The third domain (success value) points to the motive to succeed in doing a certain task. It means an internal interest to perform the task. The items were formulated to reveal the importance of success and what it means to students.

3. The scale in its primary form was shown to a group of arbitrators to explore their opinions of the scale. These opinions were collected, investigated, and the required modifications were made. The domains remained as they were. However, some items were discarded, while others were modified. By this, the scale which consisted of 15 items became ready for field application on the sample that was mentioned before.

4. From the results of field application, factor analysis was conducted to determine the number of factors which items are clustered around (the main domains of the scale) and the saturation of items with the factors (to determine the items belonging to each domain). The scale items were rearranged and two items were omitted. 
5. Ensuring the construct validity of the scale items correlation with the total degree and with the domain they are included in. Testing of the scale reliability was conducted by using the test-retest method and the internal consistency methods.

\section{Study Results and Discussion}

\section{Results Related to the First Question}

What is the significance of the validity of the scale that is expressed by the significance of face validity, content validity, factor validity, and the validity of the item correlation with the total degree of the scale and the domain that they are included in?

\section{First: Face Validity}

Face validity of the scale was confirmed in its primary form by showing it to 13 arbitrators including university faculty specialized in Curriculum and Instruction of Science, Educational Psychology, and Evaluation and Assessment. This is in addition to educational supervisors and a classroom teacher who teaches the $3^{\text {rd }}$ grade of the primary stage. They were asked to give their opinions about the scale items in the light of the criteria: the appropriateness of the scale's major domains to measure the achievement motivation according to Atkinson Theory, the affiliation of the item to the area that they were classified in, the appropriateness of the scale items with what they were put for, the item accuracy, and the convenience of the used estimation scale with the respond to items. However, the scale in its primary form is presented below:

\begin{tabular}{|c|c|c|c|c|c|}
\hline Domain & No & Items & Domain & No & Items \\
\hline \multirow{7}{*}{ 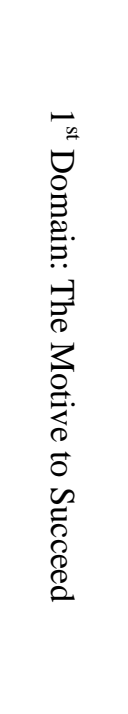 } & 1. & $\begin{array}{l}\text { I enjoy learning scientific } \\
\text { subjects }\end{array}$ & \multirow{5}{*}{ 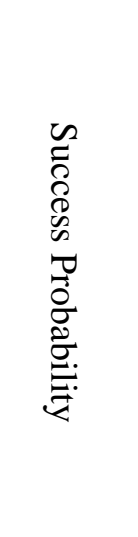 } & 12. & $\begin{array}{l}\text { I feel that I have the ability } \\
\text { to answer questions asked by } \\
\text { the science teacher }\end{array}$ \\
\hline & 2. & $\begin{array}{c}\text { I feel afraid at science } \\
\text { classes. }\end{array}$ & & 13. & $\begin{array}{l}\text { I feel worried at the time of } \\
\text { the science test. }\end{array}$ \\
\hline & 3. & $\begin{array}{l}\text { I feel time passes quickly } \\
\text { at the science class. }\end{array}$ & & 14. & $\begin{array}{c}\text { I feel other students are } \\
\text { better than me at science. }\end{array}$ \\
\hline & 4. & $\begin{array}{l}\text { I feel happy and } \\
\text { comfortable at the science } \\
\text { class. }\end{array}$ & & 15. & $\begin{array}{l}\text { I trust my ability to learn the } \\
\text { science content even if it is } \\
\text { difficult. }\end{array}$ \\
\hline & 5. & $\begin{array}{l}\text { I quickly feel bored when I } \\
\text { do the science assignments }\end{array}$ & & 16. & $\begin{array}{l}\text { I don't do the science } \\
\text { assignment if it is difficult. }\end{array}$ \\
\hline & 6. & $\begin{array}{c}\text { I like to learn more } \\
\text { difficult scientific subjects } \\
\text { than I learn now. }\end{array}$ & \multirow{2}{*}{ 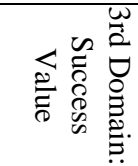 } & 17. & $\begin{array}{l}\text { I feel learning science is } \\
\text { beneficial to me in my daily } \\
\text { life. }\end{array}$ \\
\hline & 7. & I like to do easy scientific & & 18. & I feel that learning science is \\
\hline
\end{tabular}




\begin{tabular}{|c|c|c|c|c|}
\hline & & $\begin{array}{l}\text { assignments which I am } \\
\text { sure that I can achieve. }\end{array}$ & & not important for me. \\
\hline \multirow{4}{*}{ 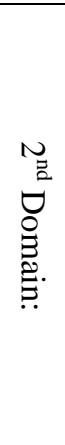 } & 8. & $\begin{array}{l}\text { I trust my ability to } \\
\text { succeed in science. }\end{array}$ & 19. & $\begin{array}{c}\text { I feel satisfied when I learn } \\
\text { new topics in science }\end{array}$ \\
\hline & 9. & $\begin{array}{l}\text { I feel that I have the ability } \\
\text { to learn scientific subjects. }\end{array}$ & 20. & $\begin{array}{l}\text { I feel that the science class } \\
\text { doesn't provide me with } \\
\text { information that benefits me } \\
\text { in my life. }\end{array}$ \\
\hline & 10. & $\begin{array}{l}\text { I can get a good mark in } \\
\text { science. }\end{array}$ & 21. & $\begin{array}{l}\text { I think of becoming an } \\
\text { inventive scientist. }\end{array}$ \\
\hline & 11. & $\begin{array}{l}\text { I feel afraid of failing in } \\
\text { the science tests. }\end{array}$ & 22. & $\begin{array}{l}\text { I feel that learning science is } \\
\text { the most important degree I } \\
\text { can get. }\end{array}$ \\
\hline
\end{tabular}

In the light of the arbitrators' comments, some items were omitted, while others were modified. Arbitrators indicated that some items represent attitudes towards science, and not achievement motivation. Some items were also modified so that their wording fits the level of the $3^{\text {rd }}$ grade students. Finally, the scale consisted of 15 items with 8 items positively formulated (1, $4,6,7,9,11,13,14)$. On the other hand, the remaining items were negatively formulated $(2,3,5,8,10,12)$. Presented below is the scale after making the modifications suggested by the arbitrators:

\begin{tabular}{|c|c|c|c|c|c|}
\hline Domain & No & Items & Domain & No & Items \\
\hline \multirow{4}{*}{ 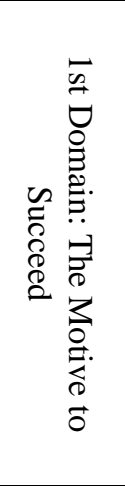 } & 1. & $\begin{array}{l}\text { I learn science because it } \\
\text { is more important than } \\
\text { the mark I get. }\end{array}$ & \multirow{3}{*}{ 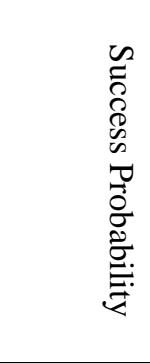 } & 8. & $\begin{array}{l}\text { I can't succeed in the } \\
\text { science tests. }\end{array}$ \\
\hline & 2. & $\begin{array}{l}\text { I avoid doing difficult } \\
\text { science activities. }\end{array}$ & & 9. & $\begin{array}{l}\text { I think of becoming an } \\
\text { inventive scientist. }\end{array}$ \\
\hline & 3. & $\begin{array}{l}\text { I attribute my failure in } \\
\text { performing science tasks } \\
\text { to their difficulty. }\end{array}$ & & 10. & $\begin{array}{l}\text { Each time I experience } \\
\text { any difficulty in doing the } \\
\text { science assignment, I give } \\
\text { up. }\end{array}$ \\
\hline & 4. & $\begin{array}{l}\text { I have the ability to learn } \\
\text { more difficult scientific } \\
\text { subjects than I learn now. }\end{array}$ & \multirow{5}{*}{ 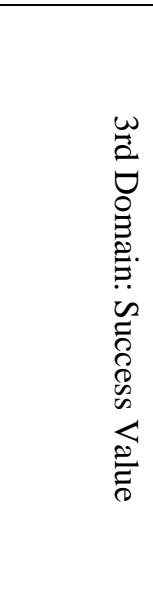 } & 11. & $\begin{array}{l}\text { I learn science because it } \\
\text { is beneficial to my life. }\end{array}$ \\
\hline \multirow{4}{*}{$\begin{array}{l}\text { 乏. } \\
\Xi \\
\oslash \\
\Xi \\
\stackrel{\Xi}{\Xi} .\end{array}$} & 5. & $\begin{array}{l}\text { I do the easy science } \\
\text { assignments which I am } \\
\text { sure of doing. }\end{array}$ & & 12. & $\begin{array}{l}\text { I study science subjects to } \\
\text { please my teacher. }\end{array}$ \\
\hline & 6. & $\begin{array}{l}\text { I trust my ability to } \\
\text { succeed in science. }\end{array}$ & & 13. & $\begin{array}{l}\text { I learn science topics } \\
\text { because they provide me } \\
\text { with new information. }\end{array}$ \\
\hline & 7. & $\begin{array}{l}\text { I can get a good mark in } \\
\text { science. }\end{array}$ & & 14. & $\begin{array}{l}\text { I have the ability to } \\
\text { answer the questions } \\
\text { asked by my teacher. }\end{array}$ \\
\hline & 8. & $\begin{array}{l}\text { I can't succeed in the } \\
\text { science tests. }\end{array}$ & & 15. & $\begin{array}{l}\text { I learn the difficult } \\
\text { science subjects with } \\
\text { enthusiasm }\end{array}$ \\
\hline
\end{tabular}




\section{Second: Content Validity}

Content validity was ensured because the scale was constructed based on one of the cognitive theories which is Atkinson theory. Hence, this theory addresses the achievement motivation. The scale consisted of three domains, namely: motivation to achieve success, success probability, and success value. These domains are considered the major factors that lead to achievement motivation. They were previously pointed out in detail.

\section{Third: Factor Validity}

The sample size sufficiency to carry out the analysis was validated through Kaiser- Meyer-Olkin test. The test value was 0.688 which is a significant value at the level of $\alpha=0.05$. Therefore, this indicates that the sample size is appropriate to do the factor analysis.

The exploratory factor analysis was carried out by using SPSS program, the basic components method, and Equamax method for rotation. Thus, this is with the aim of defining the inherent factors of the scale items. In addition, it also aims at defining the saturated items of each factor. It was found that there are three major factors (domains) of the scale items which as shown in table (1) below:

Table 1. The Three factors (domains) that constitute the scale of the achievement motivation and the saturation of the items with their factors

\begin{tabular}{|c|c|c|c|c|c|}
\hline \multicolumn{2}{|c|}{$\begin{array}{c}\text { The } 1^{\text {st }} \text { factor: Motivation to } \\
\text { achieve success }\end{array}$} & \multicolumn{2}{|c|}{$\begin{array}{l}\text { The 2nd Factor } \\
\text { Success Value }\end{array}$} & \multicolumn{2}{|c|}{$\begin{array}{c}\text { The 3rd Factor } \\
\text { Success Probability }\end{array}$} \\
\hline Item & Correlation & Item & Correlation & Item & Correlation \\
\hline 2 & 0.69 & 1 & 0.453 & 6 & 0.802 \\
\hline 3 & 0.63 & 9 & 0.589 & 7 & 0.761 \\
\hline 5 & 0.738 & 11 & 0.723 & 14 & 0.424 \\
\hline 10 & 0.662 & 12 & 0.661 & & \\
\hline 15 & 0.374 & 13 & 0.583 & & \\
\hline
\end{tabular}

Table (1) shows that the items were redistributed on the main factors (domains). Items 2, 3, 5, 10, and 15 were distributed on the first domain. The highest saturation coefficient was 0.738, while the lowest saturation coefficient was 0.453 . Items $1,9,11,12$, and 13 were distributed on the second domain. The highest saturation co-efficient was 0.723 , while the lowest coefficient of saturation was 0.453 . Items 6,7 , and 14 were distributed on the third domain. The highest saturation coefficient was 0.802 , while the lowest saturation coefficient was 0.424. However, item (8) was saturated on two factors, while item (4) was saturated on the first factor. Its saturation was 0.432 , and the second factor has a saturation of 0.524 . Item (8) was saturated on the first factor with a saturation of 0.685 , and on the third factor with a saturation of 0.42 . Therefore, they were omitted from the 
scale structure. Therefore, the following chart shows the item saturation of their factors.

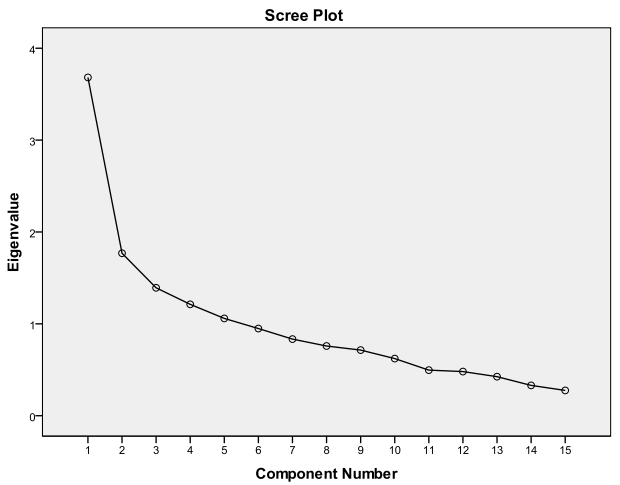

Figure 1. Graphical representation of the saturation of items with their factors

After carefully studying the items, the researchers decided to leave the name of the domains as they are. The first domain was "the motivation to achieve success"; the second domain was "the success value"; while the third domain was "success probability". Furthermore, the scale became ready in its final form as follows:

\begin{tabular}{|c|c|c|c|c|}
\hline Domain & No. & $\begin{array}{l}\text { Previous } \\
\text { No. }\end{array}$ & $\begin{array}{l}\text { Positive/negative } \\
\text { item }\end{array}$ & The Item \\
\hline \multirow{5}{*}{ 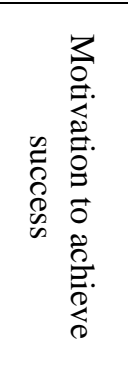 } & 1 & 2 & - & I avoid doing difficult science assignments. \\
\hline & 2 & 3 & - & $\begin{array}{l}\text { I attribute my failure of doing the science } \\
\text { assignments to their difficulty. }\end{array}$ \\
\hline & 3 & 5 & - & $\begin{array}{l}\text { I do the easy science assignments that I am } \\
\text { sure of being able to do. }\end{array}$ \\
\hline & 4 & 10 & - & $\begin{array}{l}\text { When I find difficulty in doing the science } \\
\text { assignment, I give up on it. }\end{array}$ \\
\hline & 5 & 15 & + & $\begin{array}{l}\text { I learn the difficult science subjects with } \\
\text { enthusiasm. }\end{array}$ \\
\hline \multirow{5}{*}{ 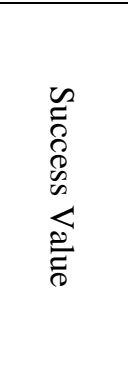 } & 6 & 1 & + & $\begin{array}{l}\text { I learn science because it is more important } \\
\text { than the marks I get. }\end{array}$ \\
\hline & 7 & 9 & + & I think of becoming an inventive scientist. \\
\hline & 8 & 11 & + & $\begin{array}{l}\text { I learn the science subjects because they are } \\
\text { beneficial to me in life. }\end{array}$ \\
\hline & 9 & 12 & + & $\begin{array}{l}\text { I study science subjects to please my } \\
\text { teacher. }\end{array}$ \\
\hline & 10 & 13. & + & $\begin{array}{l}\text { I like to learn the science subjects because } \\
\text { they provide me with new information. }\end{array}$ \\
\hline \multirow{3}{*}{ 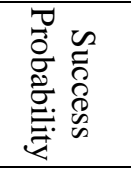 } & 11 & 6 & + & I trust my ability to succeed in science. \\
\hline & 12 & 7 & + & I can get a good mark in the science tests. \\
\hline & 13 & 14 & + & $\begin{array}{l}\text { I have the ability to answer the questions } \\
\text { asked by my teacher. }\end{array}$ \\
\hline
\end{tabular}




\section{Fourth: The Construct Validity}

The construct validity was ensured through calculation of the item correlation with the total degree and the item correlation with the domain degree

\section{1) The Item Correlation with the Total Degree}

For the purpose of calculating the correlation coefficient among the individuals' degrees on each item of the scale items and their degrees on the scale as a whole, Pearson correlation coefficient was used. Table (2) presents these values:

Table 2. The Correlation Coefficient of the items with the total degree of the scale

\begin{tabular}{|c|c|c|c|c|c|c|c|}
\hline Item No. & Item 1 & Item 2 & Item 3 & Item 5 & Item 6 & Item 7 & Item 9 \\
\hline $\begin{array}{c}\text { Correlation } \\
\text { Coefficient }\end{array}$ & $.526^{* *}$ & $.550^{* *}$ & $.533^{* *}$ & $.510^{* *}$ & $.358^{* *}$ & $.428^{* *}$ & $.477^{* *}$ \\
\hline $\begin{array}{c}\text { Item No. } \\
\text { Correlation } \\
\text { Coefficient }\end{array}$ & $.469^{* *}$ & $.332^{* *}$ & $.404^{* *}$ & $.483^{* *}$ & $.518^{* *}$ & & \\
\hline
\end{tabular}

**means that the values are significant at the level of $(\alpha=0.01)$

Table (2) illustrates that the correlation coefficient of the items with the total degree ranged between 0.332 and 0.550 . These values indicate that the scale has good validity significance. The lowest value was for the item (I learn science subjects because they benefit me in my life). It is significant at the level of $\alpha=0.01$. The highest value was for the item (I avoid doing the difficult science activities). It is also significant at the level of $\alpha=0.01$.

\section{2) The Validity of the Items' Correlation with the Domain}

The correlation coefficient between the individuals' degrees on each item of the scale items and their degrees on the domain that includes the item was calculated for the purpose of ensuring the scale construct validity. Table (3) presents these values:

Table 3. Correlation coefficient of items and the domains they are affiliated to

\begin{tabular}{|c|c|c|c|c|c|}
\hline \multirow{2}{*}{ First Domain } & Item 2 & Item 3 & Item 5 & Item 10 & Item 15 \\
\cline { 2 - 6 } & $.687^{* *}$ & $.694^{* *}$ & $.686^{* *}$ & $.616^{* *}$ & $.550^{* *}$ \\
\hline \multirow{3}{*}{ Second Domain } & Item 1 & Item 9 & Item 11 & Item 12 & Item 13 \\
\cline { 2 - 5 } & $.617^{* *}$ & $.631^{* *}$ & $.631^{* *}$ & $.6508^{*}$ & $.611^{* *}$ \\
\hline \multirow{2}{*}{ Third Domain } & Item 6 & Item 7 & Item 14 & & \\
\cline { 2 - 4 } & $.481^{* *}$ & $.438^{* *}$ & $.474^{* *}$ & \\
\hline
\end{tabular}

Table (3) shows that the correlation coefficients of the items in the factor (domain) ranged between 0.55 and 0.694. This indicates that the correlation of the items is strong regarding the first domain. The lowest value 
was for the item (I learn difficult science subjects with enthusiasm). This value is significant at the level of $\alpha=0.01$. The highest value was for the item (I attribute my failure of doing the science assignments to their difficulty). Hence, this value is significant at the level of $\alpha=0.01$.

The correlation coefficient of the items in the second domain (factor) ranged from 0.611 and 0.650 . This indicates that the correlation of the items is strong regarding the second domain. The lowest value was for the item (I learn science because it is more important than the marks I get). This value is significant at the level of $\alpha=0.01$. The highest value was for the item (I study science subjects to please my teachers). This value is also significant at the level of $\alpha=0.01$.

The correlation coefficient of the items in the third domain (factor) ranged from 0.438 and 0.481 . This indicates that the correlation of the items is strong regarding the third domain. The lowest value was for the item (I can get a good mark in the science tests). This value is significant at the level of $\alpha=0.01$. The highest value was for the item (I trust in my ability to succeed in science). This value is also significant at the level of $\alpha=0.01$.

It seems that the correlation coefficients of the items with their domains were higher in general than the correlation coefficients of the items at the total degree. This indicates that the formulation of the items is precise and accurate, Furthermore, the scale measures what it is prepared to measure especially when it is prepared in the light of a well-known theory.

\section{Results Related to Question 2:}

The reliability of the scale was ensured through internal consistency using Cronbach's Alpha coefficient and stability by using the "retest" methods.

\section{First: Internal Consistency Method (Cronbach's Alpha)}

The internal consistency of the scale items was ensured by using Cronbach's Alpha. Reliability coefficient was 0.703. This value indicates that the scale has good significance. Thus, these values are considered appropriate for the purposes of the study.

\section{Second: Retest Method}

The scale reliability was ensured by using the "retest" method to measure the stability coefficient. The scale was applied on the study sample. The application was repeated after two weeks. The correlation coefficient between the first and second application was calculated and was found to be 0.802. This is a high value which indicates that the scale has good reliability significance. 


\section{Conclusion}

The achievement motivation scale that was prepared to achieve the aims of this study consisted of three main areas that represent the main factors that lead to the identifying of the achievement motivation among students. These areas are: the motivation to achieve success, the success value, and the probability of success. The scale consisted, in its final form, of 13 items with some of these items being positive and taking the form of gradation $(1,2,3)$. On the other hand, the other items were negative and they also take the form of gradation $(3,2,1)$. The scale has an acceptable validity and reliability significance. The range of the item correlation was 0.3320.550. The correlation coefficients of the items with their domains were 0.438-0.694. The correlation coefficient of the scale reliability by using Cronbach's Alpha was 0.703 and by using test-retest was found to be 0.802 .

\section{Recommendations}

Since the scale was found to have acceptable psychometric specifications, the following recommendations could be raised:

- To use the scale and benefit from it in measuring achievement motivation towards science for the primary stage students.

- To work on the development of other scales for other educational stages.

- To work on the development of achievement motivation scales for other subjects of the study.

\section{References:}

Abdul-Hadi, N (2004). Contemporary Educational Models, Amman, Dar Wa'el for Publishing and Distribution.

Abu-Allam, R (2010). Learning: Foundations and Applications, $2^{\text {nd }}$ ed., Amman, Al-Masira for publishing, distribution and Printing.

Abu-Jadou, S (2012). Educational Psychology, 9th ed., Amman: Al-Masira for publishing and distribution.

Abu-Reyash et al. (2006). Motivation and Emotional Intelligence, Amman: Dar Al-Fikr.

Alawneh, S (2004). The Psychology of Human Development from Childhood to Adulthood, Amman, Dar Al-Masira for Publishing and Distribution.

Al-Jalali, L (2011). Academic Achievement, Amman: Al-Masira for publishing, distribution and Printing.

Al-Mubasher, Z (2009). The Effect of Using Co-Education Strategy on $10^{\text {th }}$ Grade Students' Achievement in Islamic Education Subject and their Achievement Motivation in Private Schools. Unpublished Ph.D Dissertation, The University of Jordan, Amman, Jordan. 
Al-Muhsen, Sa (2006). Perceived Self Efficiency and its Relation with Achievement Motivation, Compatibility and Achievement among the Students of Faculty of Education at Yarmuk University, Unpublished M.Ed Thesis, Yarmuk University, Irbid, Jordan.

Al-Obeidi, M (2009). Educational Psychology and its Applications, Amman: Dar Al-Thaqafa for Publishing and Distribution.

Al-Otoum et al. (2008). Educational Psychology, Theory and Practice, $2^{\text {nd }}$ ed., Amman: Dar Al-Fikr.

Al-Qudah, M \& Tartouri, M (2006). Foundations of Educational Psychology: Theory and Practice, Amman: Dar Al-Hamed for Publishing and Distribution.

Al-Zghoul, I \& Al-Hindawi, A (2010). An Introduction to Psychology, AlAin: Dar Al-Kitab Al-Jame’ei.

Al-Zghoul, I (2012). Principles of Educational Psychology, $4^{\text {th }}$ ed., Amman, Al-Masira for publishing and distribution.

Al-Ziqq, A (2006). Psychology, Amman: Dar Wa’el.

Decaro, D; DEcaro, M \& Rittle-Johnson, B (2015). Achievement motivation and knowledge development during exploratory learning. Learning \& Individual Differences, 37, 13-26. DOI: 10.1016/j.lindif.2014.10.2015.

Forgeard, M. J. C., \& Seligman, M. E. P. (2012). Seeing the glass half full: A review of the causes and consequences of optimism. Pratiques Psychologiques, 18(2), 107-120.

doi:10.1016/j.prps.2012.02.002.

Froman, L. (2010). Positive Psychology in the Workplace. Journal of Adult Development, 17(2), 59-69. doi: 10.1007/s10804-009-9080-0.

Giorgi, G., \& Majer, V. (2009). WOMI. Work and Organizational Motivational Inventory. Firenze: Giunti O.S.

Khalifah, A (2000). Achievement Motivation, Cairo: Dar Gharib for Printing, Publishing and Distribution.

Kriegbaum, K \& Spinath, B (2016). Explaining social disparities in Mathematical achievement:The role of motivation. European Journal of Personality, 30(1): 45-63. DOI: 10.1002/per.2042

Nasr, O (2004). Low Achievement Level and School Achievement: Reasons and Remedy, Amman: Dar Wa'el for Publishing and Distribution.

Musa, F (1987). Brochure test motivation to accomplish for children and adults Help. Cairo: Library of Egyptian Nahdha.

Qatami, Y \& Adas, A (2002). General Psychology, Amman, Dar Al-Fikr for Printing and Publishing.

Qatami, Y (2005). Educational Psychology and Thinking, Amman: Dar Hanin for Publishing and Distribution.

Petri, H, \& Govern, J (2004). Motivation: Theory, Research and Applications. Australia:Thomson- Wadsworth. 
Rao, M (2003). Achievement motivation and achievement in mathematics. New Delhi: Discovery Publishing House.

Sabri, M (2005). The Efficiency of a Teaching - Learning Program in Teaching Optimism and Developing Cognitive Motivation and Achievement Motivation among $6^{\text {th }}$ Grade Students of South and North Amman UNRWA Schools in Jordan, Unpublished M.Ed Thesis, University of Jordan, Amman, Jordan.

Sansone, C (2000), Intrinsic and extrinsic motivation the search for optimal motivation and performance. San Diego: Academic Press.

Sumita Rao, K (2012). Construction of Achievement Motivation Scale, Research Papers, Indian Streams Research Journal, 2, (1):1-4, 12pp.

Santrock, J (2003). Psychology. McGraw Hill, Boston.

The Ministry of Education (2013). General Framework and Public and Private Outputs of Science Subject, Directorate of Curricula and School Textbooks: Ministry of Education, Amman, Jordan.

Touq, M, Qatami, Y, \& Adas, A (2003). Foundations of Educational Psychology, $3^{\text {rd }}$ ed., Amman: Dar Al-Fikr for printing and Publishing.

Tuan, H, Chin, C, \& Shieh, S (2005). The development of a questionnaire to measure student's motivation towards science learning. International Journal of Science Education, 27 (6), 639-654.

Waugh, R (2002). Creating a scale to measure motivation to achieve academically: Linking attitudes and behaviours using Rasch measurement. British Journal of Educational Psychology, 72 (1),65-86.

Woolflok, A (2001). Educational Psychology. (8 ${ }^{\text {th }}$ ed), Boston: Allyn and Bacon.

Ziad, M (2004). The Relationship between Achievement Motivation and Class Atmosphere among $12^{\text {th }}$ Grade Students at the Arabic Private and Public Schools at Nasserite, Unpublished M.Ed Thesis, University of Jordan, Amman, Jordan. 